\title{
Nitrogen distribution and ammonia release from the overlying water and sediments of Poyang Lake, China
}

\author{
Zhiping Yang $\cdot$ Lingqing Wang $\cdot$ Tao Liang • \\ Manxiang Huang
}

Received: 17 June 2014/ Accepted: 20 January 2015/Published online: 31 January 2015

(C) Springer-Verlag Berlin Heidelberg 2015

\begin{abstract}
Poyang Lake is the largest freshwater lake in China and is one of the two largest lakes connected with the Yangtze River. It is an overflow lake which absorbs and releases water seasonally. To evaluate the geochemical cycling of nitrogen $(\mathrm{N})$ in Poyang Lake, the spatial distributions of ammonia nitrogen $\left(\mathrm{NH}_{4}{ }^{+}-\mathrm{N}\right)$, nitrate nitrogen $\left(\mathrm{NO}_{3}{ }^{-}-\mathrm{N}\right)$ and total nitrogen (TN) in sediments and overlying water were measured. The experimental results showed that the average concentrations of TN in the sediment samples, surface water, and bottom water samples from Poyang Lake were $1,107.375 \mathrm{mg} \mathrm{kg}^{-1}, 1.998$ and $2.237 \mathrm{mg} \mathrm{L}^{-1}$, respectively. The highest concentrations of TN were measured in the water and sediment obtained from the river tail region south of Poyang Lake, with decreasing pattern from south to north affected by the river input. The contribution of TN to the internal load played an important role on $\mathrm{N}$ distribution in the overlying water. The vertical distribution of $\mathrm{TN}$ in sediment cores of Poyang Lake showed a decreasing trend with depth. $\mathrm{The} \mathrm{NH}_{4}{ }^{+}-\mathrm{N}$ content in sediment cores initially decreased with depth and then increased slowly. The $\mathrm{NO}_{3}{ }^{-}-\mathrm{N}$ content in sediment cores exhibited an inverse trend compared with that of $\mathrm{NH}_{4}{ }^{+}-\mathrm{N}$ due to the influence of nitrification and denitrification processes. Release kinetic experiments of $\mathrm{NH}_{4}{ }^{+}-\mathrm{N}$ demonstrated that the maximum $\mathrm{NH}_{4}{ }^{+}-\mathrm{N}$ release rate occurred within first 5 min and reached $90-94 \%$ of the maximum value within $0-10 \mathrm{~min}$.
\end{abstract}

\footnotetext{
Z. Yang · L. Wang $(\bowtie) \cdot$ T. Liang $(\bowtie) \cdot$ M. Huang

Key Laboratory of Land Surface Pattern and Simulation,

Institute of Geographical Sciences and Natural Resources

Research, Chinese Academy of Sciences, Beijing 100101, China

e-mail: wanglq@igsnrr.ac.cn

T. Liang

e-mail: liangt@igsnrr.ac.cn
}

Keywords Sediment - Overlying water - Nitrogen · Ammonia release $\cdot$ Eutrophication

\section{Introduction}

Nitrogen $(\mathrm{N})$ is an essential nutrient for primary production in aquatic ecosystems and the growth of algae and vascular plants in freshwater ecosystems is significantly influenced by the supply of N (Spears et al. 2008; Nyenje et al. 2010; Chong et al. 2012; Xu et al. 2012; Ye et al. 2014). Eutrophication originating from excessive nutrient loading is a serious environmental problem which leads to the degradation of lake and reservoir ecosystems (Cao et al. 2011; Muhid et al. 2013; Hou et al. 2014). Eutrophication is often caused by a disturbance in nutrient and algae dynamics driven by external nutrient loading and internal recycling (Havens et al. 2001; Ye et al. 2014). Eutrophication results in a deterioration in water quality due to the increased growth of undesirable algae and aquatic weeds followed by oxygen depletion due to biomass death and decomposition (Smith et al. 1999; Xie et al. 2007; Ye et al. 2014).

Sediment plays a major role in the transportation and transformation of nutrients in freshwater ecosystems (Wang et al. 2003; Hasegawa et al. 2010; Chong et al. 2012; Lu et al. 2012; Antunes et al. 2013). Nutrients which accumulate in sediment can exchange with the overlying water via interstitial water through mechanisms such as physical attraction, chemical adsorption, and cation bridging (Hua et al. 2007; Rex and Petticrew 2010; Jiang et al. 2014). The release mechanism is known to be affected by a number of factors, including water temperature, salinity, $\mathrm{pH}$, dissolved oxygen, oxidation-reduction potential, organic matter, and hydraulic disturbances (Domagalski et al. 2007; Spears et al. 2008; Rex and 
Petticrew 2010; Zhang et al. 2012). The complex interplay among these factors largely influences the distribution and speciation of nitrogen compounds in lake sediment. Therefore, understanding the $\mathrm{N}$ cycling mechanisms at the sediment-water interface is necessary to fully quantify the impacts of lake eutrophication.

Nutrients are not necessarily adsorbed permanently by sediments, but may be released via chemical and biological processes following changes in environmental conditions (Nyenje et al. 2010; Pedro et al. 2013). In the current study, the spatial distributions of ammonia nitrogen $\left(\mathrm{NH}_{4}{ }^{+}-\mathrm{N}\right)$, nitrate nitrogen $\left(\mathrm{NO}_{3}{ }^{-}-\mathrm{N}\right)$, and total nitrogen $(\mathrm{TN})$ in sediments and the overlying water were measured to investigate the geochemical characteristics of nutrients in Poyang Lake. Release kinetics experiments with $\mathrm{NH}_{4}{ }^{+}-\mathrm{N}$ were used to evaluate the exchange mechanisms of $\mathrm{N}$ at the sediment-water interface and to estimate the risk of sediment $\mathrm{N}$ release.

\section{Materials and methods}

\section{Site description}

Poyang Lake, the largest freshwater lake in China, was used for flood control, irrigation, transportation, water supply, fishery, and tourism. The lake is located on the south bank of the Yangtze River, in northern Jiangxi Province, China, and at $115^{\circ} 49^{\prime}-116^{\circ} 46^{\prime} \mathrm{E}$ and $28^{\circ} 24^{\prime}-$ $29^{\circ} 46^{\prime} \mathrm{N}$ (Fig. 1). The Poyang Lake basin has a subtropical wet climate with a mean annual precipitation of $1,878 \mathrm{~mm}$, a mean annual surface evaporation of $1,044 \mathrm{~mm}$ and a mean annual temperature of $18{ }^{\circ} \mathrm{C}$, with the mean maximum temperature of $37{ }^{\circ} \mathrm{C}$ in summer and mean minimum temperature of $-3{ }^{\circ} \mathrm{C}$ in winter during 1953-2002 (Guo et al. 2008). The topography of Poyang Lake basin varies from high mountainous (maximum elevation of ca. 2,200 $\mathrm{m}$ above sea level) to alluvial plains in the lower reaches (Hua et al. 2007; Xiang and Zhou 2011). The predominant vegetation is mixed deciduous-evergreen broad-leaved forest; the southwestern coast of the Poyang Lake was used for agriculture, primarily rice cultivation (Jiang and Piperno 1999).

Poyang Lake is one of the two largest lakes connected to Yangtze River, and it has varied ecosystems and frequent exchange of nutrients at the sediment-water interface. Complicated hydrology and hydrodynamic conditions arise as a result of water transfer between the river and lake (Domagalski et al. 2007; Xiang and Zhou 2011), in turn causing complex exchange of nutrients between the sediment and overlying water.

Poyang Lake receives large quantities of water from five main rivers in Jiangxi Province: Ganjiang River, Fuhe

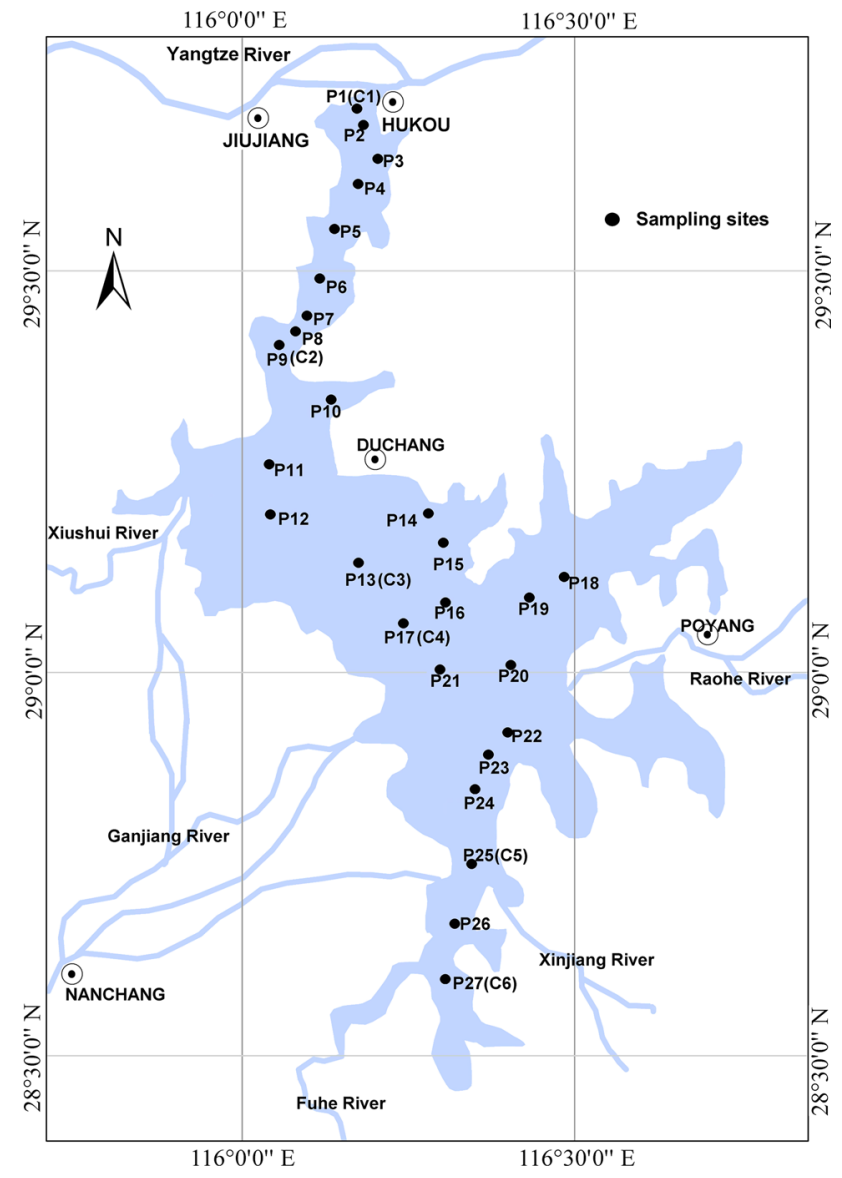

Fig. 1 Study area and sampling points in Poyang Lake

River, Xinjiang River, Raohe River and Xiushui River. The lake regulates and stores water by diverting some of this incoming water into the Yangtze River through an estuary. Large seasonal variations occur in both lake storage and lake level, with capacity controlled by catchment discharges and releases to the Yangtze River (Zhang et al. 2012; Huo et al. 2014). Flooding occurs during the rainy season from April/May to October, while during the dry season from November to April, up to $90 \%$ of lake water is lost, exposing vast grass-covered marshlands. The average lake level is $10.20 \mathrm{~m}$ (Luo et al. 2008). The highest recorded lake water level at Hukou hydrological station was $22.59 \mathrm{~m}$ (the actual highest flood level measured on the basis of Wusong Base Level) and the corresponding lake area and volume were approximately $4,500 \mathrm{~km}^{2}$ and 34 billion $\mathrm{m}^{3}$, respectively. The lowest water level at the same station was $5.90 \mathrm{~m}$, with corresponding lake area and volume values of $146 \mathrm{~km}^{2}, 450$ million $\mathrm{m}^{3}$, respectively. In recent years, increased human activity and rapid economic development have led to significant changes in the environment of Poyang Lake. The applications of fertilizers, pesticides, and herbicides, along with metal mining and smelting and petrochemical production have resulted in 
contamination of the lake with a variety of pollutants ( $\mathrm{Lu}$ et al. 2012).

Sample collection

Surface sediment samples (labeled as $P_{n}, n=1,2,3 \ldots, 27$ ) were collected at a depth of approximately $0-10 \mathrm{~cm}$ using a Van Veen Grab Sampler at 27 different sites in Poyang Lake (Fig. 1). Surface and bottom water samples were collected from each site. An aliquot of each sample was filtered through a $0.45-\mu \mathrm{m}$ filter to remove particulate matter. All water samples were stored at $4{ }^{\circ} \mathrm{C}$ prior to analysis. Six sediment cores (labeled as $C_{n}, n=1,2,3 \ldots 6$ ) were collected using a gravity stainless steel sampler with a PVC tube. The top $20 \mathrm{~cm}$ of six sediment cores were sliced into $1-\mathrm{cm}$ intervals from the surface to bottom. Sediment samples were freeze-dried and sieved through a 100-mesh sieve to remove large debris, stones and pebbles before analysis.

\section{Sample analysis}

A total of $0.2 \mathrm{~g}$ sieved sediment sample was digested using a sulfuric acid-hydrogen peroxide $\left(\mathrm{H}_{2} \mathrm{SO}_{4}-\mathrm{H}_{2} \mathrm{O}_{2}\right)$ method and the TN concentrations were determined using an alkaline potassium persulfate digestion-UV spectrophotometric method at 275 and $220 \mathrm{~nm}$ with $1 \mathrm{~cm}$ light path cuvette (Xie et al. 2007; Hou et al. 2014). The remaining sections were shaken on an orbital shaker at $200 \mathrm{rpm}$ for $1 \mathrm{~h}$ and then treated with $2 \mathrm{M} \mathrm{KCl}$. The extracts were decanted, filtered through $0.45-\mu \mathrm{m}$ filters, and frozen until analysis. Ammonium $\left(\mathrm{NH}_{4}{ }^{+}-\mathrm{N}\right)$, nitrite $\left(\mathrm{NO}_{2}{ }^{-}-\mathrm{N}\right)$, and nitrate $\left(\mathrm{NO}_{3}{ }^{-}-\mathrm{N}\right)$ levels in water samples and extracts solutions were determined using a Discrete Chemistry Analyzer (SmartChem 300, WESTCO Scientific Instruments Inc., Brookfield) (American Public Health Association 1995).

The upper parts of the six sediment cores were separated and eight sieved samples $(0.5 \mathrm{~g}$ each) were equilibrated with $50 \mathrm{ml}$ of $0.02 \mathrm{~mol} \mathrm{~L}^{-1} \mathrm{KCl}$ solution in Teflon centrifuge tubes $(100 \mathrm{~mL})$ and shaken on a horizontal shaker for $1 \mathrm{~h}$ at $25 \pm 1{ }^{\circ} \mathrm{C}$. The solutions were centrifuged at $5,000 \mathrm{rpm}$ for 5, 10, 30, 60, 90, 120, 180 and $300 \mathrm{~min}$, respectively. The supernatant was then decanted, filtered through 0.45 - $\mu \mathrm{m}$ filters, and stored at $4{ }^{\circ} \mathrm{C}$ prior to analysis for $\mathrm{NH}_{4}{ }^{+}-\mathrm{N}$. All treatments were carried out in triplicate, providing a relative measurement error of less than $5 \%$. Quality control was achieved with certified reference samples GBW07303 from the National Research Center for Certified Reference Materials (Beijing, China).

Data and statistical analyses

The release kinetics of $\mathrm{NH}_{4}{ }^{+}-\mathrm{N}$ in sediment can be described by a first-order kinetic equation (Hou et al.
2003), where $Q_{t}\left(\mathrm{mg} \mathrm{kg}^{-1)}\right.$ is the amount of $\mathrm{NH}_{4}{ }^{+}-\mathrm{N}$ released during time $t(\min ), Q_{\max }\left(\mathrm{mg} \mathrm{kg}^{-1}\right)$ is the maximum cumulative amount of $\mathrm{NH}_{4}{ }^{+}-\mathrm{N}$, and $k$ is a constant related to the release rate

$Q_{t}=Q_{\max } \times\left(1-e^{-k t}\right)$.

Differences in $\mathrm{N}$ concentrations in water and sediment samples among the sites were evaluated by analysis of variance (ANOVA). Relationships between runoff and the quantity of sediment were evaluated using Pearson's correlation coefficient. All statistical analyses were conducted using SPSS 13.0.

\section{Results and discussion}

\section{Content distribution characteristics of $\mathrm{N}$}

In recent years, increased use of fertilizers and pesticides has been accompanied by the release of large amounts of nutrients into the Poyang Lake and an aggravation of eutrophication issues (Hua et al. 2007; Jiang et al. 2014). Figure 2 shows the box charts derived from the statistical analysis that illustrated the spatial variability among different forms of $\mathrm{N}$ in water and sediment samples from Poyang Lake (Fig. 2). The average concentrations (range) of $\mathrm{TN}, \mathrm{NH}_{4}{ }^{+}-\mathrm{N}$, and $\mathrm{NO}_{3}{ }^{-}-\mathrm{N}$ were $1.998(1.053-4.469)$ $\mathrm{mg} \mathrm{L}^{-1}, \quad 0.308(0.148-0.681) \quad \mathrm{mg} \mathrm{L}^{-1}$, and 0.611 (0.298-1.140) $\mathrm{mg} \mathrm{L}^{-1}$ in surface water samples, respectively, and $2.37(1.020-5.105) \mathrm{mg} \mathrm{L}^{-1}, 0.462(0.213-$ $0.962) \mathrm{mg} \mathrm{L}^{-1}$, and $0.698(0.256-1.374) \mathrm{mg} \mathrm{L}^{-1}$ in bottom water samples, respectively (Fig. 2a).

The average concentrations of $\mathrm{TN}, \mathrm{NH}_{4}{ }^{+}-\mathrm{N}$, and $\mathrm{NO}_{3}{ }^{-}-\mathrm{N}$ in sediment samples were 1,107.375(867.082-1, 292.784) $\mathrm{mg} \mathrm{kg}^{-1}, 44.614$ (22.056-69.069) $\mathrm{mg} \mathrm{kg}^{-1}$, and 44.614 (8.129-22.167) $\mathrm{mg} \mathrm{kg}^{-1}$, respectively. The average percentages (range) of $\mathrm{NH}_{4}{ }^{+}-\mathrm{N}, \mathrm{NO}_{3}{ }^{-}-\mathrm{N}$ and organic nitrogen in the sediment samples were approximately $4.11 \% \quad(2.01-7.12 \%), \quad 1.21 \% \quad(0.92-1.77 \%)$, and $94.69 \%$ (90.79-96.73\%), respectively. $\mathrm{NH}_{4}{ }^{+}-\mathrm{N}$ originates from the oxidation of organic nitrogen or the transformation of organic nitrogen into ammonia nitrogen via anaerobic microbial reduction (Berman and Bronk 2003). Some of the absorbed $\mathrm{NH}_{4}{ }^{+}-\mathrm{N}$ is transferred by clay minerals within the sediments into the overlaying water, while the remaining part is oxidized into $\mathrm{NO}_{3}{ }^{-}-\mathrm{N}$ and $\mathrm{NO}_{2}{ }^{-}{ }^{-\mathrm{N}}$ via nitrification (Xia et al. 2013). Oxidizing environment is conducive to release of $\mathrm{NO}_{3}{ }^{-}-\mathrm{N}$ and absorption of $\mathrm{NH}_{4}{ }^{+}-\mathrm{N}$, in turn promoting nitrification reactions. Conversely, a reducing environment favors $\mathrm{NH}_{4}{ }^{+}-\mathrm{N}$ release and $\mathrm{NO}_{3}{ }^{-}-\mathrm{N}$ absorption as well as denitrification reactions (Dodsworth et al. 2011). 

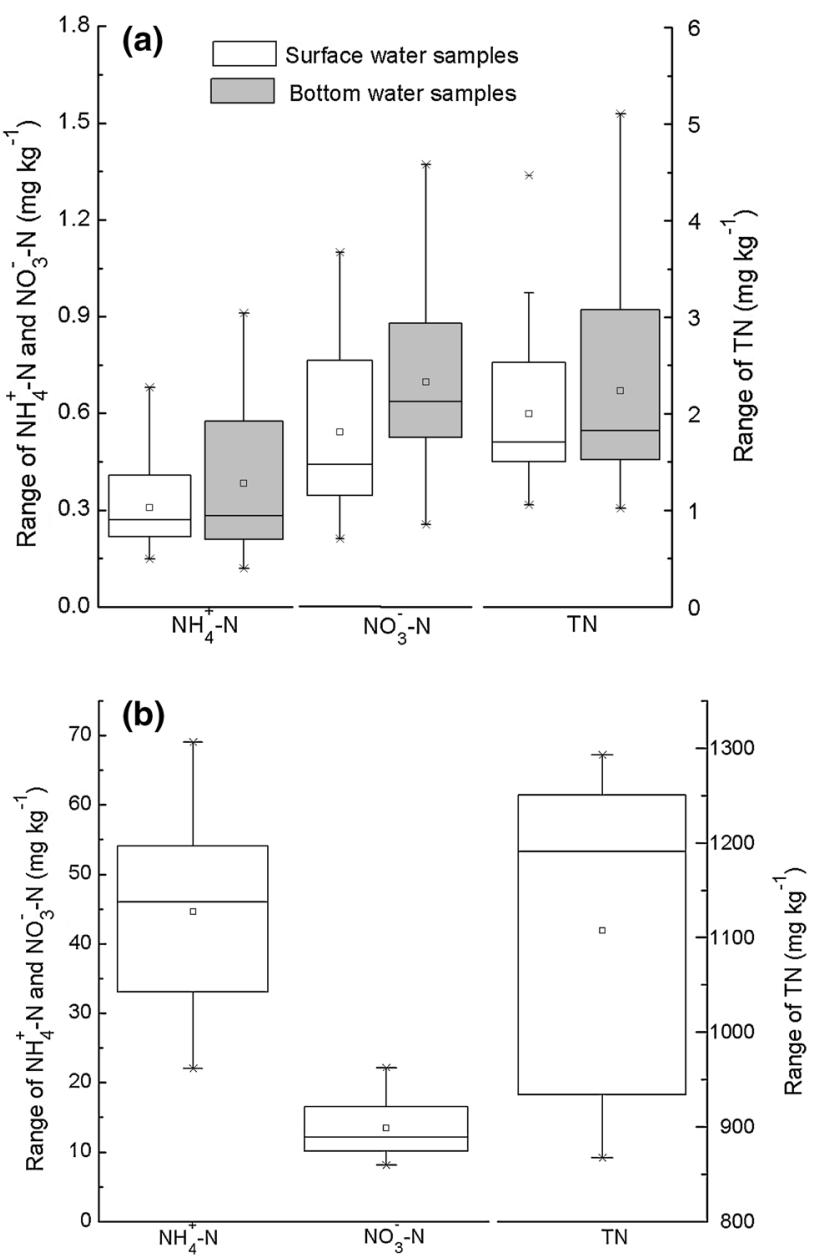

Fig. 2 Box chart of $\mathrm{NH}_{4}{ }^{+}-\mathrm{N}, \mathrm{NO}_{3}{ }^{-}-\mathrm{N}$ and $\mathrm{TN}$ contents in water samples (a) and sediment samples (b) of Poyang Lake
The spatial distribution of $\mathrm{N}$

In the downstream river channel of Poyang Lake flowing to Yangtze River (sampling sites P1-P9), the average content (range) of TN in sediment samples was $1,023.75 \mathrm{mg} \mathrm{kg}^{-1}$ $\left(867.08-1,292.78 \mathrm{mg} \mathrm{kg}^{-1}\right)$. The $\mathrm{N}$ content of sites P10P12 was higher than that of other river channel sampling sites, with an average TN concentration of 1,265.51 $\mathrm{mg} \mathrm{kg}^{-1}\left(1,214.13-1,289.76 \mathrm{mg} \mathrm{kg}^{-1}\right)$. This discrepancy can be attributed to the input of the Ganjiang River (Fig. 3). As a result of population increase, the amount of sewage discharged into the Ganjiang River has increased in recent years. In the intermediate retention area (sampling sites P13-P19), the TN content was relatively low as a result of high amounts of dilution, with an average value of $1,011.24 \mathrm{mg} \mathrm{kg}^{-1}\left(883.51-1,254.42 \mathrm{mg} \mathrm{kg}^{-1}\right)$. Due to the input of several rivers into the southern region of Poyang Lake (sampling sites P20-P27), nutrients carried by sewage tend to circulate and deposit near deltas, producing higher $\mathrm{TN}$ content compared with other regions. The average content (range) of TN in sediment samples of these sampling sites was $1,238.77 \mathrm{mg} \mathrm{kg}^{-1} \quad(1,202.04-1,285.81$ $\mathrm{mg} \mathrm{kg}^{-1}$ ), primarily originating from urban sewage, industrial wastewater, and agricultural drains.

When an external load (e.g., runoff of nutrients) is effectively controlled, an internal load may still be released from sediments as a result of water level fluctuation or hydraulic disturbance. This internal load can be significant such that it prevents improvements in water quality in a lake, even when the external load has been greatly reduced (Hua et al. 2007; Spears et al. 2008; Antunes et al. 2013).
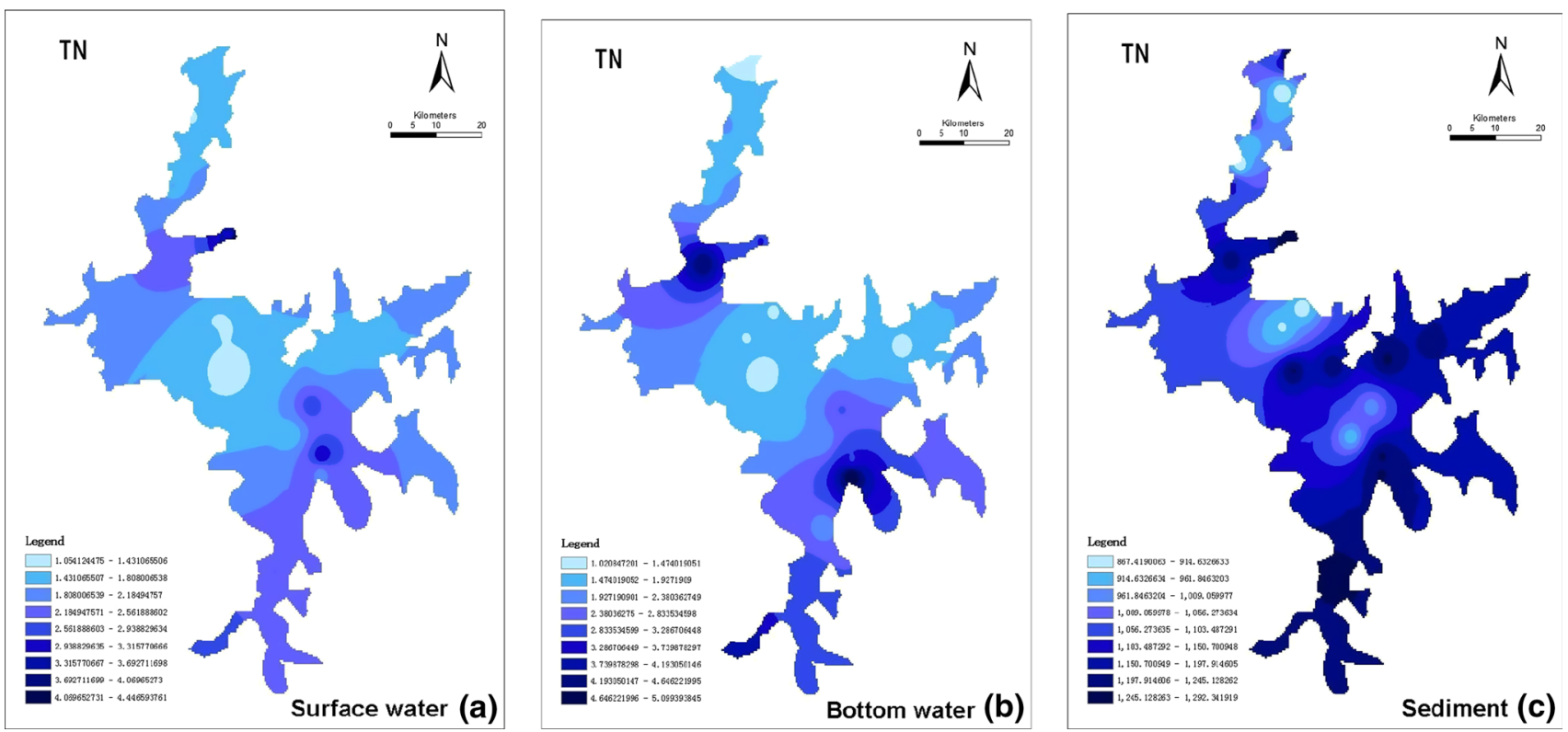

Fig. 3 Spatial distribution characteristics of TN in Poyang Lake 
Although a marked nutrient release from bottom sediment is usually associated with excessive external nutrient loading, a reduction in the external load may not necessarily affect the internal load (Dodsworth et al. 2011; Xia et al. 2013). The content and speciation of $\mathrm{N}$ in the sediments of Poyang Lake are controlled by the amount of pollutants entering the lake and the physical, chemical and hydrological conditions of the lake.

In general, high TN concentrations in water and sediments were concentrated in the southern region of Poyang
Lake and displayed a decreasing trend from south to north. In comparison, there was a positive correlation among $\mathrm{TN}$ contents in surface sediment and water samples (surface water and bottom water) $(P<0.01)$, suggesting that the nitrogen content in sediments plays an important role on the distribution of $\mathrm{N}$ in overlying water. The potential risk of $\mathrm{N}$ release from sediment is relatively high and, while controls have been established regarding the amount of external $\mathrm{N}$ inputs, internal $\mathrm{N}$ release has become the important source of the trophic state level of Poyang Lake.
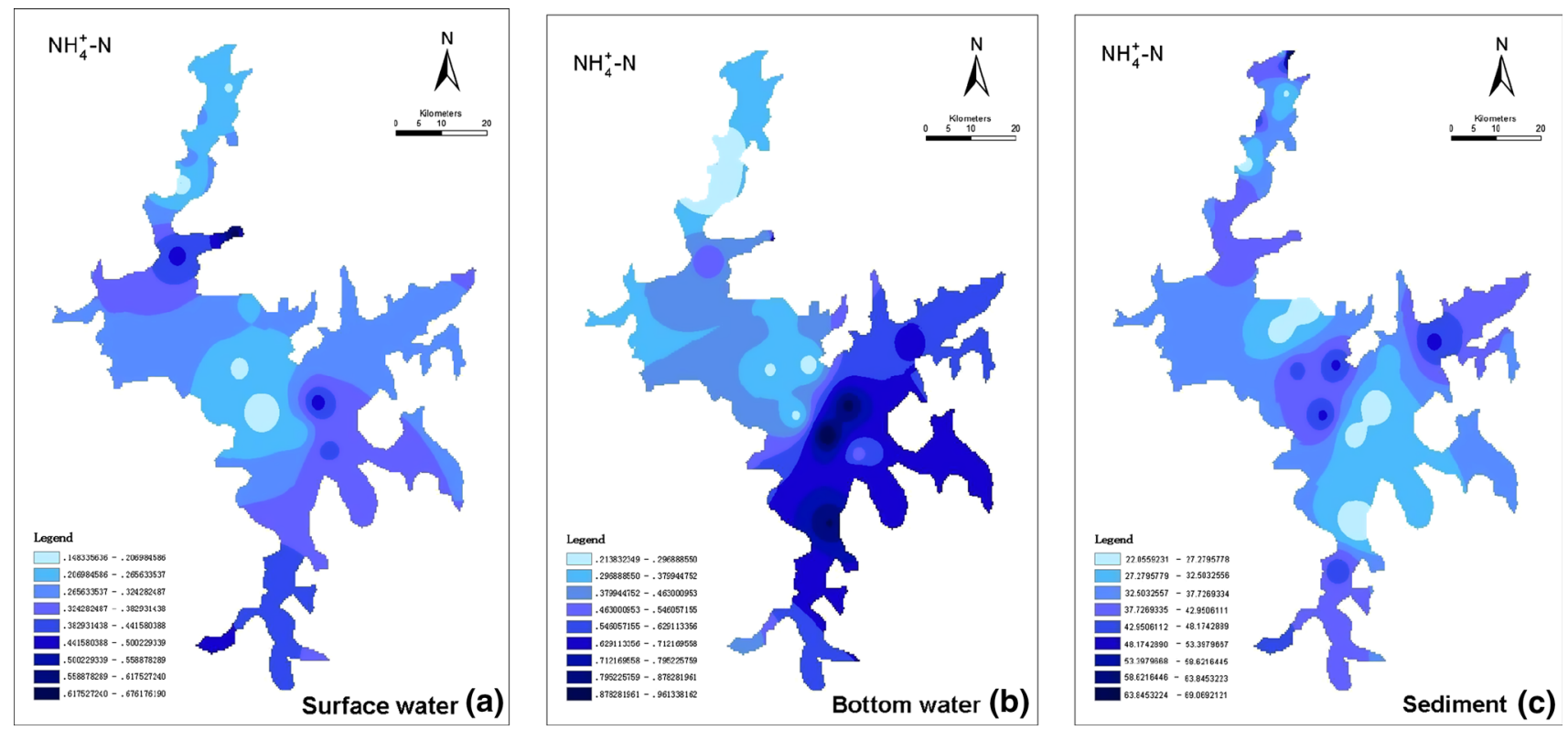

Fig. 4 Spatial distribution characteristics of $\mathrm{NH}_{4}{ }^{+}-\mathrm{N}$ in Poyang Lake
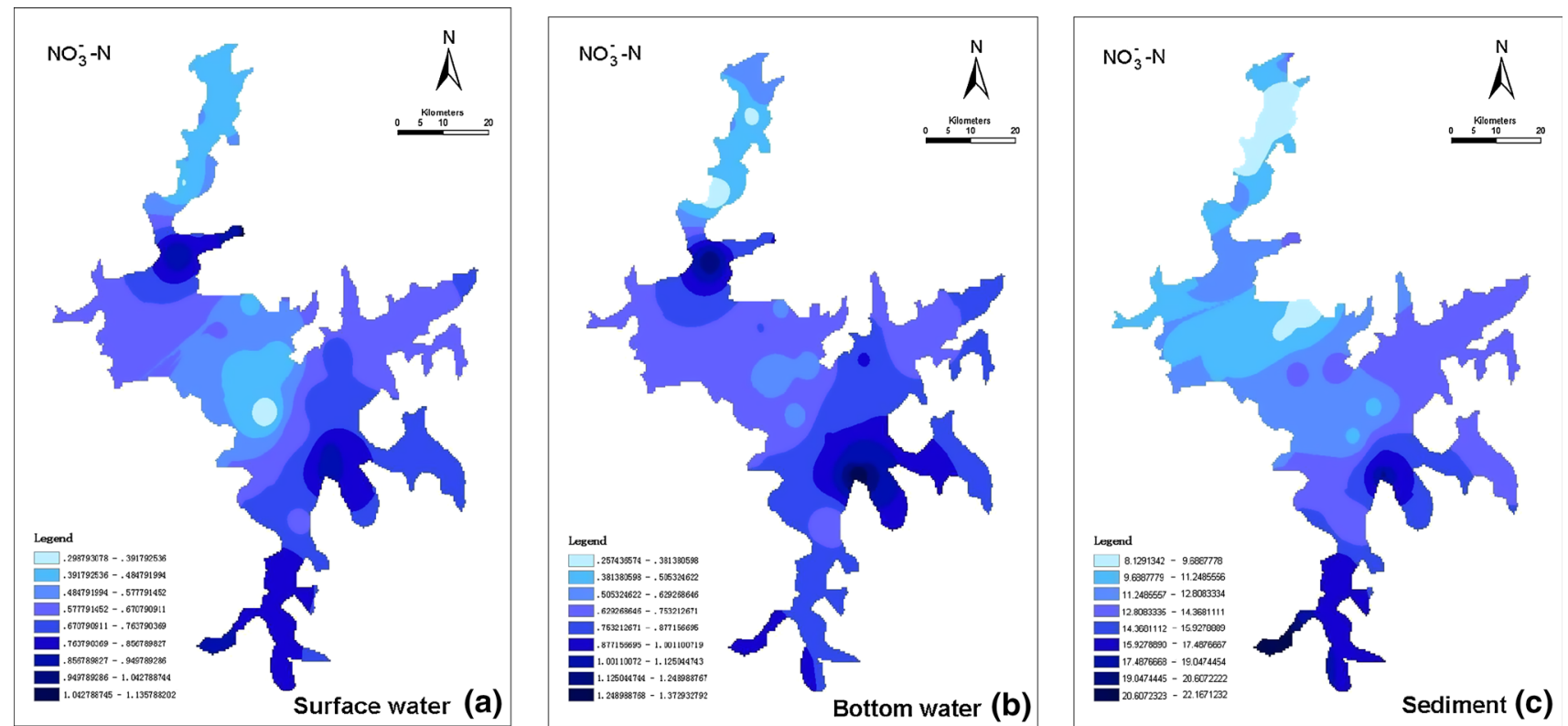

Fig. 5 Spatial distribution characteristics of $\mathrm{NO}_{3}{ }^{-}-\mathrm{N}$ in Poyang Lake 
As shown in Figs. 4 and 5, there were similar spatial distributions of $\mathrm{NH}_{4}{ }^{+}-\mathrm{N}, \mathrm{NO}_{3}{ }^{-}-\mathrm{N}$, and $\mathrm{TN}$ in the water and sediments of Poyang Lake, indicating that $\mathrm{NH}_{4}{ }^{+}-\mathrm{N}$ and $\mathrm{NO}_{3}{ }^{-}-\mathrm{N}$ concentrations were relatively high in tail area of main river in the southern region of Poyang Lake. These results demonstrated a decreasing trend in $\mathrm{N}$ concentrations from south to north. The concentrations of $\mathrm{NH}_{4}{ }^{+}-\mathrm{N}$ and $\mathrm{NO}_{3}{ }^{-}-\mathrm{N}$ were higher in bottom water than in surface water, and there was a positive relationship among those in surface sediment samples, surface and deep water samples. Results also illustrated a dynamic equilibrium between sediment and overlying water. The $\mathrm{N}$ cycle at the sediment-water interface is governed by resuspension, bioturbation, and redox conditions (Hou et al. 2014), with migration and exchange between sediments and the overlying water layer governing $\mathrm{N}$ distribution (Xia et al. 2013).

\section{Vertical distribution of $\mathrm{N}$}

The content of $\mathrm{NH}_{4}{ }^{+}-\mathrm{N}$ in sediment cores decreased in the surface layer $(0-8 \mathrm{~cm})$, and varied at depths below $8 \mathrm{~cm}$. The variation in $\mathrm{NH}_{4}{ }^{+}-\mathrm{N}$ content was more evident in sediment core $\mathrm{C} 6$ and smallest in $\mathrm{C} 3$ (Fig. 6a). The lowest values of $\mathrm{NH}_{4}{ }^{+}-\mathrm{N}$ occured in the middle section $(4-8 \mathrm{~cm})$ of each sediment core. Compared with the surface section of a sediment core, the bottom section is usually in a hypoxic state with little nitrification (Fenn et al. 2010). The bottom sections are more suitable to growth of anaerobic microorganisms, denitrification and ammonification processes, and also more conducive to $\mathrm{NH}_{4}{ }^{+}-\mathrm{N}$ accumulation than the surface sediments due to lower turbulence (Dodsworth et al. 2011). $\mathrm{NH}_{4}^{+}-\mathrm{N}$ concentrations were slightly higher in the deeper sections of sediment cores over $10 \mathrm{~cm}$ than in the shallow sediments.

The vertical variation in $\mathrm{NO}_{3}{ }^{-}-\mathrm{N}$ concentrations in the sediment cores was $30-90 \mathrm{mg} \mathrm{kg}^{-1}$. In general, the content of $\mathrm{NO}_{3}{ }^{-}-\mathrm{N}$ increased with depth in the shallow layer, reached a maximum concentration at $4-8 \mathrm{~cm}$, and then decreased in layers deeper than $8 \mathrm{~cm}$ (Fig. 6b). This trend is due to invasion of oxygenized water to sediment layers which oxidize $\mathrm{NH}_{4}{ }^{+}-\mathrm{N}$ into $\mathrm{NO}_{3}{ }^{-}-\mathrm{N}$. The content of $\mathrm{NO}_{3}{ }^{-}-\mathrm{N}$ reached a maximum value at the point where higher $\mathrm{NH}_{4}{ }^{+}-\mathrm{N}$ content inhibited organic matter decomposition under oxidizing conditions, in turn allowing nitrification to occur. Upon an increase in depth, the oxygen inversion and reduction in the sediment increased (Antunes et al. 2013). Any $\mathrm{NO}_{3}{ }^{-}-\mathrm{N}$ generated can then be used as oxidant in the decomposition of organic matter ( $\mathrm{Ye}$ et al. 2014). The content of $\mathrm{NO}_{3}{ }^{-}-\mathrm{N}$ reached a maximum value at 4-8 cm, and then decreased with depth. The variation in $\mathrm{NO}_{3}{ }^{-}-\mathrm{N}$ content was most significant in sediment core $\mathrm{C} 2$ and negligible in $\mathrm{C} 1$.
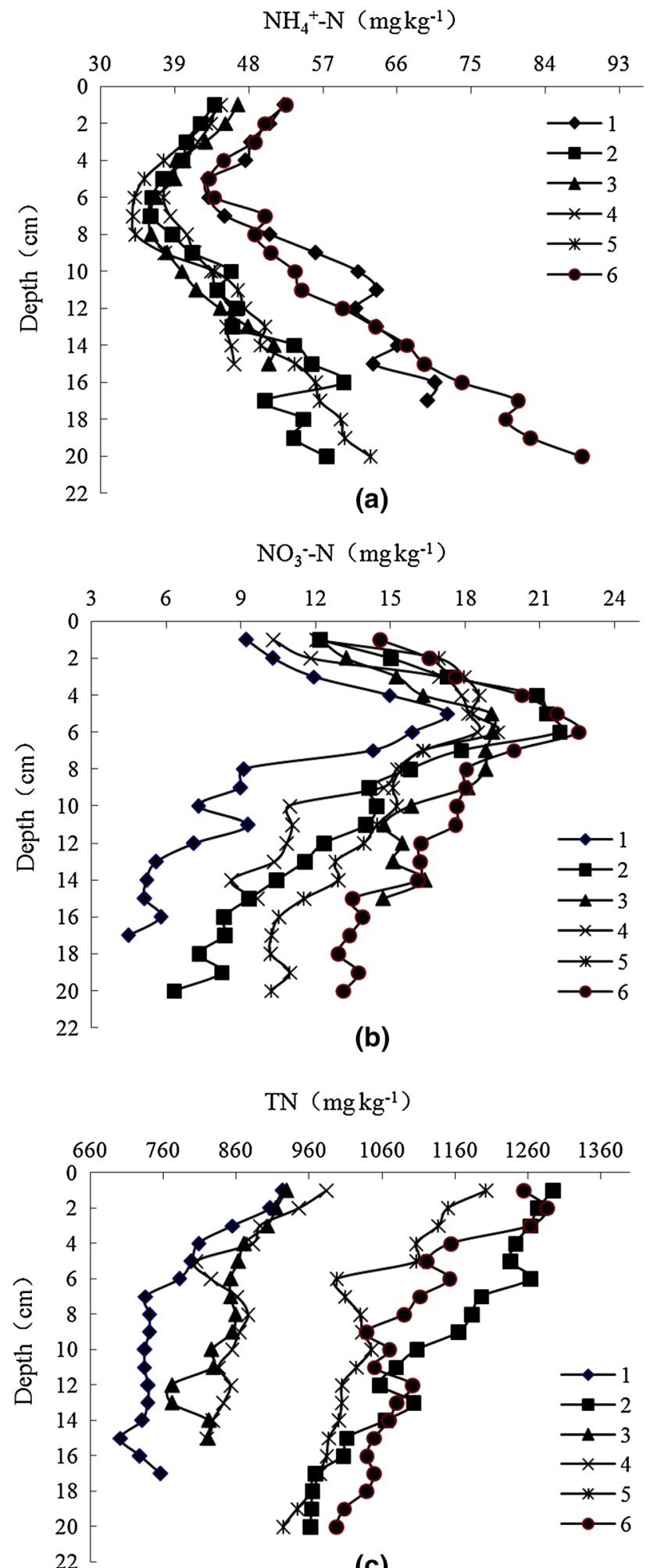

(c)

Fig. 6 Vertical distribution of $\mathrm{NH}_{4}{ }^{+}-\mathrm{N}, \mathrm{NO}_{3}{ }^{-}-\mathrm{N}$ and $\mathrm{TN}$ in sediment cores of Poyang Lake

The average $\mathrm{TN}$ content (range) in sediment cores was 971.35 (701.71-1,294.22) $\mathrm{mg} \mathrm{kg}^{-1}$. The surface layer of sediment cores contained the highest $\mathrm{TN}$ content, and 


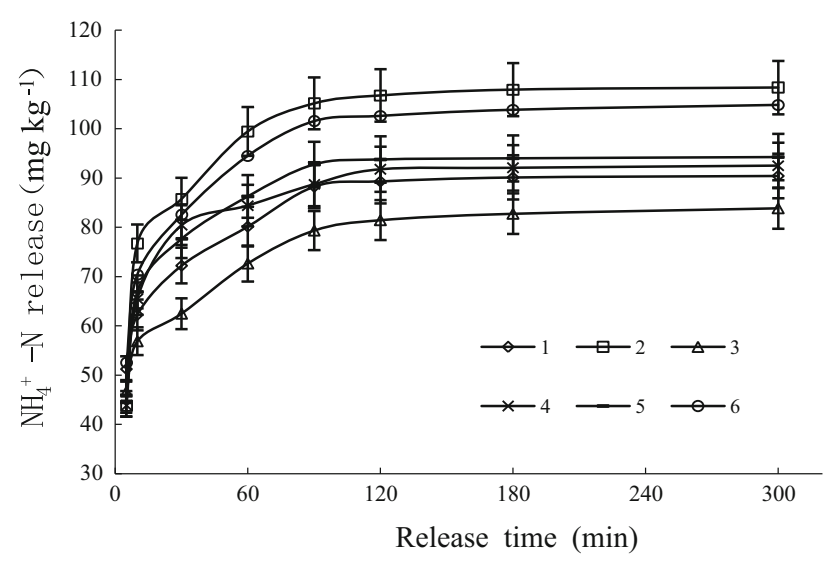

Fig. 7 The release kinetic curve of $\mathrm{NH}_{4}^{+}-\mathrm{N}$ in the surface sediments of Poyang Lake

decreased with depth. Among these sediment cores, the TN contents in sediment cores $\mathrm{C} 1, \mathrm{C} 3$ and $\mathrm{C} 4$ were lower than those in $\mathrm{C} 2$, C5, and C6 (Fig. 6c). These results suggest that the lake regions containing $\mathrm{C} 2, \mathrm{C} 5$, and $\mathrm{C} 6$ coincide with the influx of rivers, which feed large amounts of terrigenous nutrients into the lake.

Release characteristics of $\mathrm{NH}_{4}{ }^{+}-\mathrm{N}$ in surface sediment

$\mathrm{N}$ is primarily released from sediment as $\mathrm{NH}_{4}-\mathrm{N}$, which is efficiently converted to $\mathrm{NO}_{3}-\mathrm{N}$ via aerobic nitrification (Beutel 2006; Spears et al. 2008; Fenn et al. 2010). In previous studies, release kinetics experiments with $\mathrm{NH}_{4}{ }^{+}-$ $\mathrm{N}$ were conducted to investigate the exchange mechanisms of $\mathrm{N}$ at the sediment-water interface and estimate the risk of lake eutrophication caused by the sediment $\mathrm{N}$ release (Morin and Morse 1999; Fenn et al. 2010; Ye et al. 2014).

As shown in Fig. 7, a similar trend in $\mathrm{NH}_{4}^{+}-\mathrm{N}$ release was observed in surface sediments among the six selected sites. The release of $\mathrm{NH}_{4}{ }^{+}-\mathrm{N}$ rapidly increased in first $120 \mathrm{~min}$ and then gradually increased to a maximum value. The fitting parameters for the release kinetics of $\mathrm{NH}_{4}{ }^{+}-\mathrm{N}$ are shown in Table 1.

The release kinetics of $\mathrm{NH}_{4}{ }^{+}-\mathrm{N}$ in the surface sediments was accurately captured by the first-order kinetic equation $\left(R^{2}=0.69-0.92, P<0.01\right)$. The average $Q_{\max }$ value of $\mathrm{NH}_{4}{ }^{+}-\mathrm{N}$ release was $90.671(85.173-103.404) \mathrm{mg} \mathrm{kg}^{-1}$. The maximum releases of $\mathrm{NH}_{4}{ }^{+}-\mathrm{N}$ and $\mathrm{TN}$ in the surface sediments of Poyang Lake showed a significant positive correlation $(P<0.05)$. The $\mathrm{NH}_{4}{ }^{+}-\mathrm{N}$ release increased with an increase in TN content.

To further investigate the $\mathrm{NH}_{4}{ }^{+}-\mathrm{N}$ release in sediments, the release rate was calculated (per unit time per unit mass of $\mathrm{NH}_{4}{ }^{+}-\mathrm{N}$ release). The release rate reached a maximum value of $8.75-10.25 \mathrm{mg}(\mathrm{kg} \mathrm{min})^{-1}$ in first $5 \mathrm{~min}$ and gradually decreased $5 \mathrm{~min}$. After $120 \mathrm{~min}$, the release rate
Table 1 The fitting parameters of the first-order kinetic equation of $\mathrm{NH}_{4}{ }^{+}-\mathrm{N}$ release in sediments of Poyang Lake

\begin{tabular}{lcccccc}
\hline \multirow{2}{*}{$\begin{array}{l}\text { Model } \\
\text { parameters }\end{array}$} & \multicolumn{6}{l}{ Surface samples of sediment core } \\
\cline { 2 - 7 } & 1 & 2 & 3 & 4 & 5 & 6 \\
\hline$Q_{\max }$ & 85.173 & 103.404 & 77.226 & 88.775 & 90.542 & 98.907 \\
$K$ & 0.153 & 0.116 & 0.154 & 0.132 & 0.129 & 0.131 \\
$R^{2}$ & 0.77 & 0.89 & 0.69 & 0.94 & 0.90 & 0.85 \\
\hline
\end{tabular}

Table 2 The release rate of $\mathrm{NH}_{4}{ }^{+}-\mathrm{N}$ in surface sediments of Poyang Lake in different intervals

\begin{tabular}{lllllll}
\hline Time/min & \multicolumn{7}{l}{ Release rate $\mathrm{mg}(\mathrm{kg} \mathrm{min})^{-1}$} \\
\cline { 2 - 7 } & 1 & 2 & 3 & 4 & 5 & \multicolumn{1}{l}{6} \\
\hline $0-5 \mathrm{~min}$ & 10.25 & 8.75 & 9.33 & 8.77 & 8.91 & 10.49 \\
$>5-10 \mathrm{~min}$ & 6.22 & 7.67 & 5.68 & 6.55 & 6.68 & 7.04 \\
$>10-30 \mathrm{~min}$ & 2.41 & 2.85 & 2.08 & 2.68 & 2.58 & 2.75 \\
$>30-60 \mathrm{~min}$ & 1.33 & 1.65 & 1.21 & 1.41 & 1.41 & 1.56 \\
$>60-90 \mathrm{~min}$ & 0.98 & 1.17 & 0.88 & 0.98 & 1.03 & 1.12 \\
$>90-120 \mathrm{~min}$ & 0.74 & 0.88 & 0.67 & 0.76 & 0.78 & 0.85 \\
$>120-180 \mathrm{~min}$ & 0.51 & 0.59 & 0.45 & 0.51 & 0.52 & 0.57 \\
$>180-300 \mathrm{~min}$ & 0.31 & 0.36 & 0.27 & 0.31 & 0.31 & 0.35 \\
\hline
\end{tabular}

decreased to nearly zero. A rapid release of $\mathrm{NH}_{4}{ }^{+}-\mathrm{N}$ occurred in 0-10 min. The $\mathrm{NH}_{4}{ }^{+}-\mathrm{N}$ release amount in the first 5 min was $40-57 \%$ of the maximum value and reached $90-94 \%$ of the maximum value in $0-10 \mathrm{~min}$ (Table 2). The release rates of $\mathrm{NH}_{4}{ }^{+}-\mathrm{N}$ in $0-5$ min and 0-10 min were both significantly higher than those in the remaining time. After $120 \mathrm{~min}$, the $\mathrm{NH}_{4}{ }^{+}-\mathrm{N}$ release reached $97-99 \%$ of the maximum value. The release rate of $\mathrm{NH}_{4}{ }^{+}-\mathrm{N}$ and the content of TN in sediments have significant positive correlation during the first $5 \mathrm{~min}$ $(P<0.05)$.The $\mathrm{NH}_{4}{ }^{+}-\mathrm{N}$ release rates increased with an increase in $\mathrm{TN}$ content in sediments.

\section{Conclusions}

The highest concentrations of $\mathrm{TN}$ in water and sediment were mainly located in the river tail region of southern Poyang Lake. The TN concentrations tended to decrease from south to north with a spatial distribution dependent on river input. A positive correlation was also found among $\mathrm{TN}$ in surface sediments, surface and bottom water. Specifically, the internal load of $\mathrm{N}$ in sediment influenced the $\mathrm{N}$ distribution in overlying water. The vertical distribution of $\mathrm{TN}$ in sediment cores exhibited a decreasing trend with increasing depth. $\mathrm{NH}_{4}{ }^{+}-\mathrm{N}$ contents in sediment cores initially decreased with depth and then increased slowly to a maximum value, while the $\mathrm{NO}_{3}{ }^{-}-\mathrm{N}$ distribution exhibited 
an opposite trend. A first-order kinetic model curve was able to capture the $\mathrm{NH}_{4}{ }^{+}-\mathrm{N}$ release process in the surface sediment of Poyang Lake. The release process reached completion after $120 \mathrm{~min}$. Positive correlations were also found among release rate, maximum release of $\mathrm{NH}_{4}{ }^{+}-\mathrm{N}$, and $\mathrm{TN}$ content in sediments.

Acknowledgments This study was sponsored by the National Key Project for Basic Research (No. 2012CB417004) and the National Natural Scientific Foundation of China (No. 41401591 and 41171390). We also thank the anonymous reviewers for their helpful comments to improve the manuscript.

\section{References}

American Public Health Association (1995) In: Greenburg AE, Clesceri LS, Eaton AD (eds) Standard methods for the examination of water and wastewater, twentieth edn. American Public Health Association, Washington, DC

Antunes M, Antunes MT, Fernandes AN et al (2013) Nutrient contents in bottom sediment samples from a southern Brazilian microbasin. Environ Earth Sci 69(3):959-968

Berman T, Bronk DA (2003) Dissolved organic nitrogen: a dynamic participant in aquatic ecosystems. Aquat Microb Ecol 31(3):279-305

Beutel MC (2006) Inhibition of ammonia release from anoxic profundal sediments in lakes using hypolimnetic oxygenation. Ecol Eng 28:271-279

Cao C, Zheng B, Chen Z et al (2011) Eutrophication and algal blooms in channel type reservoirs: a novel enclosure experiment by changing light intensity. J Environ Sci 23:1660-1670

Chong LS, Prokopenko MG, Berelson WM et al (2012) Nitrogen cycling within suboxic and anoxic sediments from the continental margin of Western North America. Mar Chem 128:13-25

Dodsworth JA, Hungate BA, Hedlund BP (2011) Ammonia oxidation, denitrification and dissimilatory nitrate reduction to ammonium in two US Great Basin hot springs with abundant ammoniaoxidizing archaea. Environ Microbiol 13(8):2371-2386

Domagalski J, Lin C, Luo Y et al (2007) Eutrophication study at the Panjiakou-Daheiting Reservoir system, northern Hebei Province, People's Republic of China: chlorophyll-a model and sources of phosphorus and nitrogen. Agr Water Manage 94:43-53

Fenn ME, Allen EB, Weiss SB et al (2010) Nitrogen critical loads and management alternatives for $\mathrm{N}$-impacted ecosystems in California. J Environ Manage 91:2404-2423

Guo H, Hu Q, Jiang T (2008) Annual and seasonal streamflow responses to climate and land-cover changes in the Poyang Lake basin, China. J Hydrol 355(1):106-122

Hasegawa H, Rahman MA, Kitahara K et al (2010) Seasonal changes of arsenic speciation in lake waters in relation to eutrophication. Sci Total Environ 408:1684-1690

Havens KE, Fukushima T, Xie P et al (2001) Nutrient dynamics and the eutrophication of shallow lakes Kasumigaura (Japan), Donghu (PR China), and Okeechobee (USA). Environ Pollut 111:263-272

Hou LJ, Liu M, Jiang HY et al (2003) Ammonium adsorption by tidal flat surface sediments from the Yangtze Estuary. Geology 45:72-78

Hou D, He J, Lü C et al (2014) Spatial variations and distributions of phosphorus and nitrogen in bottom sediments from a typical north-temperate lake, China. Environ Earth Sci 71(7):3063-3079
Hua Q, Feng S, Guo H et al (2007) Interactions of the Yangtze River flow and hydrologic processes of the Poyang Lake, China. J Hydrol 347:90-100

Huo S, Zhang J, Xi B et al (2014) Distribution of nitrogen forms in surface sediments of lakes from different regions, China. Environ Earth Sci 71(5):2167-2175

Jiang QH, Piperno DR (1999) Environmental and archaeological implications of a late quaternary palynological sequence, Poyang Lake, Southern China. Quat Res 52:250-258

Jiang T, Huo S, Xi B et al (2014) The influences of land-use changes on the absorbed nitrogen and phosphorus loadings in the drainage basin of Lake Chaohu, China. Environ Earth Sci 71(9):4165-4176

Lu M, Zeng D, Liao Y et al (2012) Distribution and characterization of organochlorine pesticides and polycyclic aromatic hydrocarbons in surface sediment from Poyang Lake, China. Sci Total Environ 433:491-497

Luo M, Li J, Cao W et al (2008) Study of heavy metal speciation in branch sediments of Poyang Lake. J Environ Sci 20:161-166

Morin J, Morse JW (1999) Ammonium release from resuspended sediments in the Laguna. Mar Chem 65:97-110

Muhid P, Davis TW, Bunn SE (2013) Effects of inorganic nutrients in recycled water on freshwater phytoplankton biomass and composition. Water Res 47:384-394

Nyenje PM, Foppen JW, Uhlenbrook S et al (2010) Eutrophication and nutrient release in urban areas of sub-Saharan Africa-A review. Sci Total Environ 408:447-455

Pedro T, Kimberley S, Fernando P (2013) Dynamics of phosphorus in sediments of a naturally acidic lake. Int $\mathrm{J}$ Sediment Res 28:90-102

Rex JF, Petticrew EL (2010) Salmon-derived nitrogen delivery and storage within a gravel bed: sediment and water interactions. Ecol Eng 36:1167-1173

Smith VH, Tilman GD, Nekola JC (1999) Eutrophication: impacts of excess nutrient inputs on freshwater, marine, and terrestrial ecosystems. Environ Pollut 100:179-196

Spears BM, Carvalho L, Perkins R et al (2008) Effects of light on sediment nutrient flux and water column nutrient stoichiometry in a shallow lake. Water Res 42:977-986

Wang H, Wang C, Wu W et al (2003) Persistent organic pollutants in water and surface sediments of Taihu Lake, China and risk assessment. Chemosphere 50:557-562

Xia X, Liu T, Yang Z et al (2013) Dissolved organic nitrogen transformation in river water: effects of suspended sediment and organic nitrogen concentration. J Hydrol 484:96-104

Xiang S, Zhou W (2011) Phosphorus forms and distribution in the sediments of Poyang Lake, China. Int J Sediment Res $26: 230-238$

Xie YX, Xiong ZQ, Xing GX et al (2007) Assessment of nitrogen pollutant sources in surface waters of taihu lake region. Pedosphere 17:200-208

Xu X, Gao B, Zhao Y et al (2012) Nitrate removal from aqueous solution by Arundo donax L. reed based anion exchange resin. J Hazard Mater 203:86-92

Ye X, Bai J, Lu Q et al (2014) Spatial and seasonal distributions of soil phosphorus in a typical seasonal flooding wetland of the Yellow River Delta, China. Environ Earth Sci 71(11):4811-4820

Zhang L, Yin J, Jiang Y et al (2012) Relationship between the hydrological conditions and the distribution of vegetation communities within the Poyang Lake National Nature Reserve, China. Ecol Inform 11:65-75 